\title{
MHC-DRB1/DQB1 Gene Polymorphism and Its Association with Resistance/Susceptibility to Cystic Echinococcosis in Chinese Merino Sheep
}

\author{
Hong Shen, Guohua Han, Bin Jia, Song Jiang, and Yingchun Du \\ College of Animal Science and Technology, Shihezi University, Xinjiang, 832003, China \\ Correspondence should be addressed to Bin Jia; jiabin@shzu.edu.cn
}

Received 13 June 2013; Revised 23 October 2013; Accepted 23 October 2013; Published 24 March 2014

Academic Editor: C. Genchi

Copyright (C) 2014 Hong Shen et al. This is an open access article distributed under the Creative Commons Attribution License, which permits unrestricted use, distribution, and reproduction in any medium, provided the original work is properly cited.

\begin{abstract}
The aim of this study was to analyze the relationship between polymorphism of the MHC-DRB1/DQB1 gene and its resistance to Cystic Echinococcosis (C.E), as well as to screen out the molecular genetic marker of antiechinococcosis in Chinese Merino sheep. The MHCII-DRB1/DQB1 exon 2 was amplified by polymerase chain reaction (PCR) from DNA samples of healthy and hydatidosis sheep. PCR products were characterized by restriction fragment length polymorphism (RFLP) technique. Five restriction enzymes (Mval, HaeIII, SacI, SacII, and HinlI) were employed to cut DRB1, while seven restriction enzymes (MroxI, ScaI, SacII, NciI, TaqI, Mval, and HaeIII) were employed to cut DQB1.Results showed that frequencies of patterns Mvalbb $(P<0.01)$, SacIab in DRB1 exon $2(P<0.05)$, and TaqIaa, HaeIIInn $(P<0.01)$ in DQB1 exon 2 were significantly higher in the healthy group compared with the C.E individuals, which implied that there was a strong association between these genotypes and hydatidosis resistance or susceptibility. Chi-square test showed that individuals with the genic haplotype DRB1-SacIab/DRB1-Mvalbb/DQB1TaqIaa/DQB1-HaeIIInn $(P<0.01)$ were relatively resistant to C.E, while individuals with the genic haplotypes DRB1-Mvalbc/DQB1Mvalyy/DQB1-TaqIab/DQB1-HaeIIImn $(P<0.01)$ and DRB1-Mvalbb/DQB1-Mvalcc/DQB1-TaqIab/DQB1-HaeIIImn $(P<0.01)$ were more susceptible to C.E. In addition, to confirm these results, a fielding experiment was performed with Chinese Merino sheep which were artificially infected with E.g. The result was in accordance with the results of the first study. In conclusion, MHCDRB1/DQB1 exon 2 plays an important role as resistant to C.E in Chinese Merino sheep. In addition, the molecular genetic marker of antiechinococcosis (DRB1-SacIab/DRB1-Mvalbb/DQB1-TaqIaa/DQB1-HaeIIInn) was screened out in Chinese Merino sheep.
\end{abstract}

\section{Introduction}

The major histocompatibility complex (MHC) gene of sheep is located on Chromosome 20 and is called Ovar [1]. The MHC gene family includes two major subfamilies: class I and class II genes [2]. Studies have shown the existence of class II loci that are homologous to HLA-DQB [3-6]. As in other vertebrate species, a high degree of polymorphism is found in the Ovar- $D Q B$ genes, with most of the polymorphic sites located in exon 2, which encodes the antigen-binding site [7]. Due to its highly polymorphic character, a variety of studies have been applied in many fields. It has been well-reported that alleles of different MHC genes correlate with disease resistance in sheep [8]; furthermore, specific MHC alleles are associated with parasite resistance in sheep
[9]. Currently, relevant research on Ovar polymorphism and disease resistance or susceptibility mainly concentrates on Ovar-DRB1 [10-14] and Ovar-DQB $[7,15]$.

C.E is a cosmopolitan zoonotic parasitic disease caused by the larval stage (metacestode stage) of the tapeworm Echinococcus granulosus that cycles between canines, particularly dogs, as definitive hosts and various herbivores as intermediate hosts. In the intermediate hosts and humans, larvae develop into hydatid cysts in various organs, particularly the liver and lungs. C.E is associated with severe morbidity and disability, especially in pastoral areas in northwestern China, the prevalence of which not only results in a considerable decrease in livestock production, but also seriously affects the life quality of people. Chinese Merino sheep, well known as the character of well wool, is beneficial to local sheep 
husbandary; however it is relatively more susceptible to C.E. Therefore, this disease will result in low performance on Chinese Merino sheep.

At present, many studies focus on MHC-hydatid disease associations in human [16-19]. However, few reports have been published on the study of the Ovar association with C.E in sheep. In this study, efforts were made to investigate $\mathrm{MHC}$ $D R B 1 / D Q B 1$ gene polymorphism and its association with resistance/susceptibility to C.E in Chinese Merino sheep, screening out the molecular genetic marker of antiechinococcosis.

\section{Materials and Methods}

2.1. Animal Sampling and Sample Preparation. We received blood samples from 204 2-year-old Chinese Merino sheep, donated from Mission 165, agricultural division 9, Xinjiang Production and Construction Corps. The C.E sheep and healthy sheep were distinguished by ovine hydatidosis ELISA kit (Shenzhen Combined Biotech Co., Ltd.). We chose 101 C.E sheep and 103 healthy controls. Samples of genomic DNA were obtained from whole blood and stored at $-20^{\circ} \mathrm{C}$ until analysis. The major materials and reagents were obtained from Promega Company and Shanghai Sangon Biological Engineering Technology and Service Co., Ltd.

2.2. PCR Amplifications. The second exon of Ovar-DRB1 was amplified by nested PCR. The first round of PCR was performed with primers OLA-ERB1 (GC) $5^{\prime}$-CCG GAA TTC CCG TCT CTG CAG CAC ATT TCT T- $3^{\prime}$ and HL031 $5^{\prime}$-TTT AAA TTC GCG CTC ACCTCG CCG CT-3' [20]. $100 \mathrm{ng}$ of genomic DNA was used as DNA template in a total volume of $20 \mu \mathrm{L}$ PCR reaction which was composed of $1.5 \mathrm{mM} \mathrm{MgCl}_{2}$ and $120 \mu \mathrm{M}$ dNTPs, to which $0.2 \mathrm{mM}$ of each primer and $1.5 \mathrm{U}$ of Taq polymerase were added. Reactions were performed in a thermocycler under the following conditions: one cycle of initial denaturation for $5 \mathrm{~min}$ at $94^{\circ} \mathrm{C}$ followed by 15 cycles of $94^{\circ} \mathrm{C}$ for $30 \mathrm{~s}, 50^{\circ} \mathrm{C}$ for $30 \mathrm{~s}$, and $72^{\circ} \mathrm{C}$ for $60 \mathrm{~s}$, with final extension at $72^{\circ} \mathrm{C}$ for $10 \mathrm{~min}$. Three $\mu \mathrm{L}$ of first step PCR was used for the second step PCR by using primers OLAERB1(GC) and OLA-XRBI (5'-AGC TCG AGC GCT GCA CAG TGAAAC TC- $3^{\prime}$ ) [20]. The conditions were one cycle for $5 \mathrm{~min}$ at $94^{\circ} \mathrm{C}$, followed by 30 cycles of $94^{\circ} \mathrm{C}$ for $30 \mathrm{~s}, 63^{\circ} \mathrm{C}$ for $30 \mathrm{~s}$, and $72^{\circ} \mathrm{C}$ for $60 \mathrm{~s}$ with final extension at $72^{\circ} \mathrm{C}$ for $10 \mathrm{~min}$. The second exon of $D Q B 1$ was amplified by primers FW: $5^{\prime}$-CCC CGC AGA GGA TTT CGT G-3' and REV: $5^{\prime}$ ACC TCG CCG CTG CCA GGT-3' [21]; 150 ng of Genomic DNA was amplified in a total volume of $11250 \mu$ l, including $1.5 \mathrm{mM} \mathrm{MgCl} 2,100 \mu \mathrm{M}$ dNTPs, $0.2 \mathrm{mM}$ of each primer, and $2 \mathrm{U}$ of Taq polymerase. Reactions were performed in a thermo cycler under the following conditions: one cycle of initial denaturation for $5 \mathrm{~min}$ at $94^{\circ} \mathrm{C}$, followed by 33 cycles of $94^{\circ} \mathrm{C}$ for $30 \mathrm{~s}, 67^{\circ} \mathrm{C}$ for $30 \mathrm{~s}$, and $72^{\circ} \mathrm{C}$ for $45 \mathrm{~s}$, with final extension at $72^{\circ} \mathrm{C}$ for $10 \mathrm{~min}$.

2.3. RFLP. The cleavage map typing method and allele nomenclature referred to that of Konnai et al. [20]. Each $10 \mu \mathrm{L}$ of DRB1 PCR product was digested with $5 \mathrm{U}$ of SacI, Hin1I,
HaeIII, MvaI, and SacII, respectively, in a total volume of $20 \mu \mathrm{L}$, including $2 \mu \mathrm{L} 10 \times$ buffer. Each $10 \mu \mathrm{L}$ of $D Q B 1$ PCR product was digested with $5 \mathrm{U}$ of MroxI, ScaI, SacII, NciI, TaqI, MvaI, and HaeIII, respectively. Samples were resolved by agarose gel electrophoresis at varying concentrations (Table S1) (see Supplementary Material available online at http://dx.doi.org/10.1155/2014/272601).

2.4. Cloning and Sequencing. According to the typing results of restriction digest, the samples 54 and 74 were selected for cloning and sequencing, because the samples were HaeIIImm, HaeIIInn, MvaIyy, and MvaIzz genotype, which are inconsistent with the previous reports [20]. So the amplified PCR products of these samples were cloned into pGEM-T vector, the ligated plasmids was selected by bluewhite colony screening, then masculine clone were sent to sequence.

2.5. Verification of Artificial Infection with E.g. To verify the validity and reliability of the above research results, sixteen 2-year-old Chinese Merino sheep, which were negative by hydatidosis ELISA kit detection, were chosen to conduct the experiment of artificial infection with E.g. Eight of the sheep with the haplotype of DRB1-SacIab/DRB1$M v a I b b / D Q B 1-T a q I a a / D Q B 1-H a e I I I n n$ were taken as the test group, and the other eight sheep with the haplotypes of $D R B 1$ SacIab/DRB1-MvaIbc/DQB1-TaqIaa/DQB1-HaeIIInn, DRB1SacIab/DRB1-MvaIbc/DQB1-TaqIaa/DQB1-HaeIIImn,or DRB1-SacIab/DRB1-MvaIbb/DQB1-TaqIaa/DQB1-

HaeIIImm, which were not associated with hydatidosis resistance or susceptibility, were taken as the control group. Each sheep was fed 10 adult cestodes with fertilized egg proglottis by mouth. These sixteen sheep were bred under the same conditions.

2.6. Statistical Analysis. Allelic and genotypic frequencies in C.E-negative and -positive Chinese Merino sheep were analyzed by $t$-test to assess the relationship between different genotypes and C.E significance. The chi-square test was performed to analyze the relationship between the different haplotypes and C.E resistance. The C.E infection rates of the test and control groups were compared by Fisher's exact test after artificial infection with E.g.

\section{Results}

3.1. PCR Amplification. Ovar-DRB1 exon 2 was amplified by PCR with primers OLA-ERB1, OLA-HL031, and OLA-XRBI; one specific band of $296 \mathrm{bp}$ was observed on $1.5 \%$ agarose (Figure S1B). Ovar-DQB1 exon 2 was amplified by PCR with primers FW and REV, and one specific band of $280 \mathrm{bp}$ was observed on $2 \%$ agarose (Figure S1B).

3.2. PCR-RFLP. From restriction digestion of DRB1 exon 2 PCR product, genotypes of SacI, HinlI, MvaI, SacII, and HaeIII (Table S2B) were observed, and some of genotypic restriction maps were in Figure 1. In addition, genotypes of restriction enzymes MroxI, ScaI, SacII, NciI, TaqI, MvaI, 


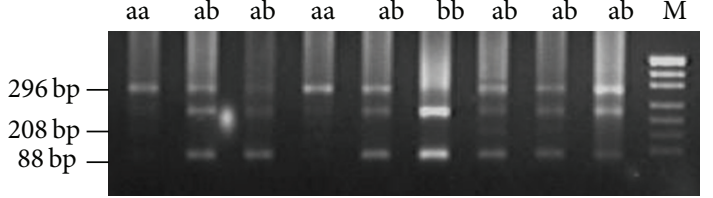

(a)

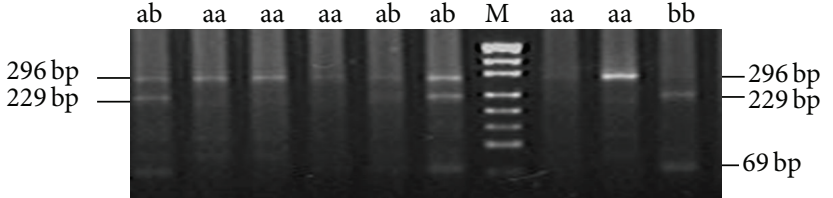

(b)

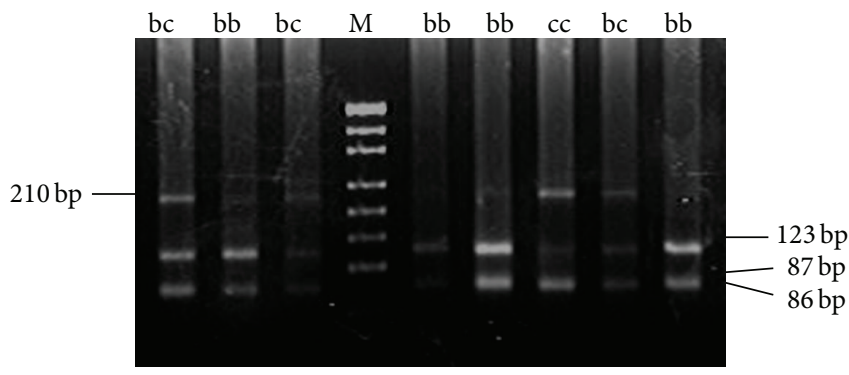

(c)

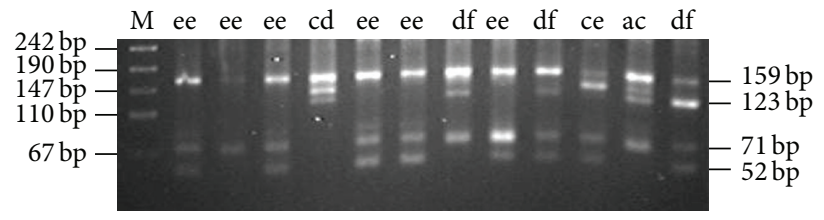

(d)

FIGURE 1: (a) Part results of electrophoretic patterns of exon 2 of MHC-DRB1 digested with SacI in Chinese Merino sheep; M: pUC19 DNA marker. (b) Part results of electrophoretic patterns of exon 2 of MHC-DRB1 digested with SacII in Chinese Merino sheep; M: pUC19 DNA marker. (c) Part results of electrophoretic patterns of exon 2 of MHC-DRB1 digested with MvaI in Chinese Merino sheep; M: pUC19 DNA marker. (d) Part results of electrophoretic patterns of exon 2 of MHC-DRB1 digested with HaeIII in Chinese Merino sheep; M: pUC19 DNA marker.

and HaeIII (Table S2B) for DQB1 PCR products were also observed, and some of their genotypic restriction maps were in Figure 2.

3.3. Anlysis of Clonig and Sequncing. We verified the predicted RFLP profiles of Ovar-DRB1 alleles by sequencing cloned 184 amplified products, and all of the observed patterns of fragments matched exactly with those predicted from DNA sequences. Sequencing of Ovar-DQB1 exon 2 cloned amplified products revealed two single point mutations, $\mathrm{T}$ to $\mathrm{G}$ and $\mathrm{A}$ to $\mathrm{G}$, at base positions 32 and 159 , respectively, resulting in new alleles, HaeIIImm and HaeIIInn. In addition, two G-to-A point mutations at base positions 96 and 246 resulted in new alleles, MvaIy and MvaIz. Comparison of sequencing results to the original sequence of DQB1 exon 2 (GenBank, accession numbers: Z28523) are shown in Figure S3.

\subsection{Analysis of the Relationship between Genotypes and C.E} Resistance. Statistical comparisons of genotypic frequencies in C.E sheep and healthy controls revealed that DRB1 genotypic frequencies of MvaIbb $(P<0.01)$, HaeIIIee, and SacIab $(P<0.05)$ in negatives were higher than in C.E sheep, indicating a strong association between these genotypes and C.E resistance, while genotypes in terms of SacIIab $(P<$ $0.05)$, HaeIIIdf $(P<0.05)$, HaeIIIbd $(P<0.01)$, and MvaIbc $(P<0.01)$ in $D R B 1$ exon 2 occurred more often in C.E individuals when compared with the healthy group, which implied that there was a strong association between these genotypes and hydatidosis susceptibility (Table 1). DQB1 genotypic frequencies of TaqIaa and HaeIIInn $(P<0.01)$, MvaIdz $(P<0.05)$ in negatives were higher than in positives, while genotypes of TaqIab and HaeIIImn $(P<0.01)$, MvaIcz
$(P<0.05)$ in positives were higher than in negatives (Table 2). Therefore, we concluded that DQB1 genotypes of TaqIaa, HaeIIInn, and MvaIdz were resistant to C.E, while genotypes of TaqIab, HaeIIImn, and MvaIcz were susceptible to C.E.

3.5. Verification of Artificial Infection with E.g. Analyzing the haplotype of resistant genotypes, it was found that the haplotype frequency of DRB1-SacIab/DRB1-MvaIbb/DQB1TaqIaa/DQB1-HaeIIInn in C.E-negative sheep was higher than in C.E sheep $(P<0.01)$, indicating that this haplotype was the resistant haplotype of Chinese Merino sheep (Table 3). The result was verified by artificial infection hydatidosis. The haplotypes of DRB1-MvaIbc/DQB1MvaIyy/DQB1-TaqIab/DQB1-HaeIIImn and DRB1MvaIbb/DQB1-MvaIcc/DQB1-TaqIab/DQB1-HaeIIImn in positives were higher than in negatives $(P<0.01)$, which implied that these haplotypes were susceptible to C.E individuals.

Protoscoleces can develop into cysts within 20 days postinfection [22]. The sixteen sheep that were artificially infected with E.g were slaughtered in the second month after E.g infection, and visual inspection of the liver and lung surfaces of each slaughtered animal was made for the detection of larval stages of cestodes [23]. Results show that 3 sheep were infected with E.g in the test group, whereas 6 sheep were infected with E.g in the control group; therefore, the infection rate in the test group was significantly lower than that of the control group $(P<0.05)$. It is confirmed that the genic haplotype DRB1-SacIab/DRB1-MvaIbb/DQB1-TaqIaa/DQB1HaeIIInn leads to C.E resistance in Chinese Merino sheep. 

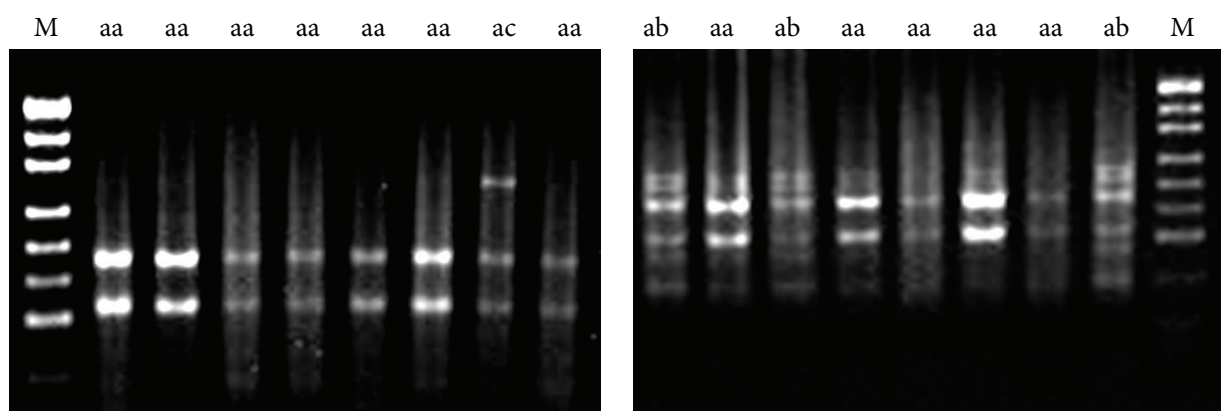

(a)
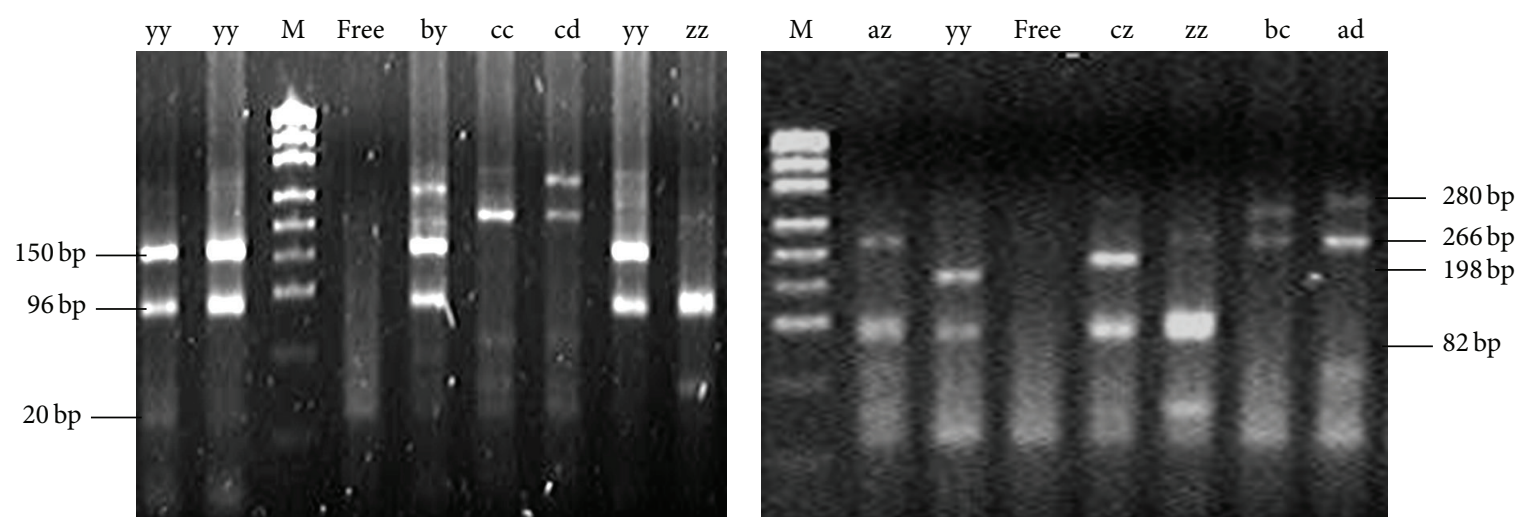

(b)

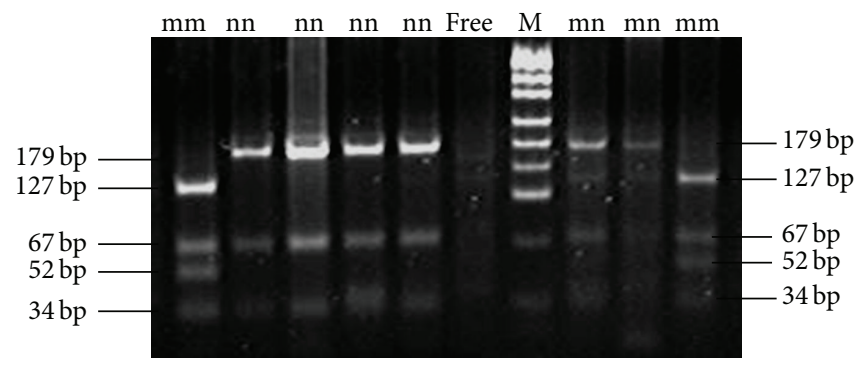

(c)

FIGURE 2: (a) Part results of electrophoretic patterns of exon 2 of MHC-DQB1 digested with TaqI in Chinese Merino sheep; M: pUC19 DNA marker. (b) Part results of electrophoretic patterns of exon 2 of MHC-DQB1. (c) Part results of electrophoretic patterns of exon 2 of MHCDQB1 digested with HaeIII in Chinese Merino sheep; M: pUC19 DNA marker.

\section{Discussion and Conclusion}

The $M H C$ gene is well known to be involved in the vertebrate immune system and encodes antigen recognition proteins used in the adaptive immune response. Polymorphism of this gene has become a hot topic in the past decades. A variety of studies, both overseas and domestic, have shown that MHC of sheep and goats introduces polybase mutation and affluent polymorphism. Amills et al. [24, 25] utilized the PCR-RFLP method to investigate polymorphism of $D R B$ in goats, Konnai et al. [20] researched the polymorphism of $D R B 1$ in some sheep, with results indicating that affluent polymorphism exists in the Ovis aries-DRB1 gene, and Dongxiao and Yuan [26] studied DRB3 polymorphism of Chinese local sheep and goats. In addition, Ovis aries- $D Q B 1$ gene investigations have been conducted abroad [21, 27], and Chinese scholars have studied MHC-DQB and DQA in human [28], swine [29], and cattle $[30,31]$. However, there are still no domestic reports of Ovis aries-DQB1. In the present study, we used MroxI, ScaI, SacII, NciI, TaqI, HaeIII, and MvaI by PCR-RFLP to analyze $D Q B 1$ exon 2 and found the existence of $2,2,4,2,3,3$, and 6 alleles, as well as $3,3,7,3,4,6$, and 16 genotypes, respectively. The results of cloning and sequencing of the alleles, that is, HaeIIIm, HaeIIIn, MvaIy, and MvaIz, indicated that they are new alleles resulted from mutation in Chinese Merino sheep.

The extensive diversity at many MHC loci provides a valuable source of genetic markers for examining the complex relationships between host genotype and disease resistance or susceptibility [10]. For example, Sayers et al. [11] suggested that the Ovar-DRB1 gene plays an important role in the enhanced resistance of Suffolk sheep to nematode infection. By comparing phenotypic frequencies of A.E patients 
TABLE 1: Genotypic frequencies of $D R B 1$ in Chinese Merino sheep with and without Cystic Echinococcosis.

\begin{tabular}{|c|c|c|c|c|c|}
\hline \multicolumn{3}{|c|}{ Cystic Echinococcosis negative } & \multicolumn{3}{|c|}{ Cystic Echinococcosis positive } \\
\hline Genotype & Number & Frequency & Genotype & Number & Frequency \\
\hline SacI aa & 42 & 0.3853 & SacI aa & 47 & 0.4700 \\
\hline SacI ab & 58 & $0.5321^{*}$ & SacI ab & 38 & 0.3800 \\
\hline SacI bb & 9 & 0.0826 & SacI bb & 15 & 0.1500 \\
\hline Hin1I aa & 15 & 0.1376 & HinlI aa & 14 & 0.1414 \\
\hline Hin1I ab & 55 & 0.5046 & HinlI ab & 43 & 0.4343 \\
\hline Hin $1 \mathrm{I} b \mathrm{~b}$ & 39 & 0.3578 & HinlI bb & 42 & 0.4243 \\
\hline SacII aa & 65 & 0.7471 & SacII aa & 50 & 0.6250 \\
\hline SacII ab & 13 & 0.1494 & SacII ab & 22 & $0.2750^{*}$ \\
\hline SacII bb & 9 & 0.1035 & SacII bb & 8 & 0.1000 \\
\hline$M v a \mathrm{I}$ aa & 1 & 0.0115 & $M v a \mathrm{I}$ aa & 0 & 0 \\
\hline$M v a \mathrm{I} b \mathrm{~b}$ & 68 & $0.7816^{* *}$ & MvaI bb & 45 & 0.5556 \\
\hline$M v a \mathrm{I} \mathrm{cc}$ & 1 & 0.0115 & $M v a \mathrm{I} c c$ & 4 & 0.0494 \\
\hline$M v a \mathrm{I}$ dd & 0 & 0 & $M v a I$ dd & 0 & 0 \\
\hline$M v a \mathrm{I} a b$ & 0 & 0 & $M v a \mathrm{I} a b$ & 0 & 0 \\
\hline$M v a \mathrm{I}$ ac & 0 & 0 & MvaI ac & 1 & 0.0124 \\
\hline$M v a \mathrm{I} b c$ & 17 & 0.1954 & MvaI bc & 31 & $0.3827^{* *}$ \\
\hline HaeIII aa & 17 & 0.1651 & HaeIII aa & 11 & 0.1100 \\
\hline HaeIII bb & 9 & 0.0874 & HaeIII bb & 4 & 0.0400 \\
\hline HaeIII cc & 5 & 0.0485 & HaeIII cc & 7 & 0.0700 \\
\hline HaeIII dd & 0 & 0 & HaeIII dd & 1 & 0.0100 \\
\hline HaeIII ee & 11 & $0.1068^{*}$ & HaeIII ee & 2 & 0.0200 \\
\hline HaeIII ff & 11 & 0.1068 & HaeIII ff & 8 & 0.0800 \\
\hline HaeIII ab & 1 & 0.0097 & HaeIII ab & 4 & 0.0400 \\
\hline HaeIII ac & 12 & 0.1165 & HaeIII ac & 13 & 0.1300 \\
\hline HaeIII ae & 1 & 0.0097 & HaeIII ae & 4 & 0.0400 \\
\hline HaeIII bd & 1 & 0.0097 & HaeIII bd & 9 & $0.0900^{* *}$ \\
\hline HaeIII be & 2 & 0.0194 & HaeIII be & 5 & 0.0500 \\
\hline HaeIII cd & 6 & 0.0583 & HaeIII cd & 0 & 0 \\
\hline HaeIII ce & 16 & 0.1554 & HaeIII ce & 7 & 0.0700 \\
\hline HaeIII df & 5 & 0.0485 & HaeIII df & 13 & $0.1300^{*}$ \\
\hline HaeIII ef & 6 & 0.0583 & HaeIII ef & 12 & 0.1200 \\
\hline
\end{tabular}

Note: the same genotypes of $D R B 1$ in Chinese Merino sheep with and without Cystic Echinococcosis, ${ }^{*} P<0.05,{ }^{* *} P<0.01$.

with healthy controls, it has been speculated that HLA$D R B 1^{*} 11$ may have a certain resistance to A.E, but HLA$D Q B 1^{*} 02$ would exacerbate the disease process [32]. The potential immunogenetic predisposition for susceptibility and resistance to unilocular echinococcosis was investigated by HLA-DRB1 typing, and a statistically significant positive association was found between HLA-DR3 and HLA-DR11, and the occurrence of C.E. HLA-DR3 antigen was positively associated with the occurrence of isolated, multiple pulmonary cysts [16]. Differences have been shown between HLA characteristics of A.E patients with different courses of E. $m$, notably the association of the HLA B8, DR3, and DQ2 haplotype with more severe forms of this granulomatous parasitic disease, which suggested that HLA characteristics of the host could influence immune-mediated mechanisms [19].
TABLE 2: Genotypic frequencies of DQB1 in Chinese Merino sheep with and without Cystic Echinococcosis.

\begin{tabular}{|c|c|c|c|c|c|}
\hline \multicolumn{3}{|c|}{ Cystic Echinococcosis negative } & \multicolumn{3}{|c|}{ Cystic Echinococcosis positive } \\
\hline Genotype & Number & Genotype & Number & Genotype & Number \\
\hline MroxI aa & 31 & 0.4493 & MroxI aa & 28 & 0.4375 \\
\hline MroxI ab & 24 & 0.3478 & MroxI ab & 25 & 0.3906 \\
\hline MroxI aa & 14 & 0.2029 & MroxI aa & 11 & 0.1719 \\
\hline ScaI aa & 10 & 0.1176 & ScaI aa & 14 & 0.1972 \\
\hline ScaI ab & 74 & 0.8706 & ScaI ab & 57 & 0.8028 \\
\hline ScaI bb & 1 & 0.0118 & ScaI bb & 0 & 0 \\
\hline NciI xx & 60 & 0.7058 & NciI xx & 66 & 0.7021 \\
\hline NciI gg & 16 & 0.1882 & NciI gg & 20 & 0.2127 \\
\hline NciI xg & 9 & 0.1058 & NciI xg & 8 & 0.0851 \\
\hline SacII aa & 25 & 0.4464 & SacII aa & 37 & 0.5968 \\
\hline SacII bb & 3 & 0.0536 & SacII bb & 0 & 0 \\
\hline SacII cc & 5 & 0.0893 & SacII cc & 7 & 0.1129 \\
\hline SacII ab & 10 & 0.1759 & SacII ab & 4 & 0.0645 \\
\hline SacII ac & 12 & 0.2143 & SacII ac & 8 & 0.1290 \\
\hline SacII ad & 1 & 0.0179 & SacII ad & 5 & 0.0806 \\
\hline SacII bd & 0 & 0 & SacII bd & 1 & 0.0161 \\
\hline TaqI aa & 85 & $0.8252^{* *}$ & TaqI aa & 58 & 0.55743 \\
\hline TaqI bb & 1 & 0.0097 & TaqI bb & 1 & 0.0099 \\
\hline TaqI ab & 17 & 0.1650 & TaqI ab & 41 & $0.4059^{* *}$ \\
\hline TaqI ac & 0 & 0 & TaqI ac & 1 & 0.0099 \\
\hline$M v a \mathrm{I}$ aa & 7 & 0.0737 & $M v a \mathrm{I}$ aa & 3 & 0.0361 \\
\hline$M v a \mathrm{I} b \mathrm{~b}$ & 0 & 0 & MvaI bb & 1 & 0.0120 \\
\hline MvaI cc & 13 & 0.1368 & $M v a \mathrm{I} \mathrm{cc}$ & 18 & 0.2169 \\
\hline$M v a \mathrm{I} d \mathrm{~d}$ & 12 & 0.1263 & $M v a \mathrm{I} d \mathrm{~d}$ & 4 & 0.0482 \\
\hline$M v a \mathrm{I} \mathrm{zz}$ & 22 & 0.2316 & $M v a \mathrm{I} \mathrm{zz}$ & 16 & 0.1928 \\
\hline MvaI yy & 15 & 0.1579 & MvaI yy & 14 & 0.1687 \\
\hline MvaI ad & 1 & 0.0105 & MvaI ad & 0 & 0 \\
\hline$M v a \mathrm{I}$ az & 3 & 0.0316 & MvaI az & 1 & 0.0120 \\
\hline MvaI bc & 0 & 0 & $M v a \mathrm{I} b c$ & 1 & 0.0120 \\
\hline$M v a \mathrm{I}$ bd & 0 & 0 & MvaI bd & 1 & 0.0120 \\
\hline MvaI bz & 0 & 0 & $M v a \mathrm{I} b z$ & 1 & 0.0120 \\
\hline MvaI by & 2 & 0.0211 & MvaI by & 0 & 0 \\
\hline MvaI cd & 3 & 0.0316 & $M v a \mathrm{I} c d$ & 6 & 0.0723 \\
\hline MvaI cz & 7 & 0.0737 & $M v a \mathrm{I} c z$ & 14 & $0.1687^{*}$ \\
\hline$M v a \mathrm{I} \mathrm{dz}$ & 9 & $0.0947^{*}$ & $M v a \mathrm{I} \mathrm{dz}$ & 2 & 0.0241 \\
\hline$M v a \mathrm{I}$ dy & 1 & 0.0105 & MvaI dy & 1 & 0.0120 \\
\hline HaeIII aa & 3 & 0.0312 & HaeIII aa & 0 & 0 \\
\hline HaeIII mm & 24 & 0.2500 & HaeIII mm & 32 & 0.3299 \\
\hline HaeIII nn & 55 & $0.5729^{* *}$ & HaeIII nn & 28 & 0.2887 \\
\hline HaeIII am & 1 & 0.0104 & HaeIII am & 3 & 0.0309 \\
\hline HaeIII an & 2 & 0.0208 & HaeIII an & 3 & 0.0309 \\
\hline HaeIII mn & 11 & 0.1146 & HaeIII mn & 31 & $0.3196^{* *}$ \\
\hline
\end{tabular}

Note: the same genotypes of $D Q B 1$ in Chinese Merino sheep with and without Cystic Echinococcosis, ${ }^{*} P<0.05,{ }^{* *} P<0.01$.

This study found that the DRB1-SacIab/DRB1-MvaIbb/DQB1TaqIaa/DQB1-HaeIIInn haplotype is echinococcosis resistant and selected the genetic markers of resistance to hydatidosis. 
TABLE 3: Assessment of the relationship between haplotype and Cystic Echinococcosis in Chinese Merino sheep.

\begin{tabular}{|c|c|c|c|}
\hline Haplotype of MHC & $\begin{array}{c}\text { Number of Cystic } \\
\text { Echinococcosis } \\
\text { positive cases }\end{array}$ & $\begin{array}{c}\text { Number of Cystic } \\
\text { Echinococcosis } \\
\text { negative cases }\end{array}$ & $\chi^{2}$ \\
\hline DRB1-SacIab/DRB1-MvaIbb/DQB1-TaqIaa/DQB1-HaeIIInn & 19 & 1 & $17.5734^{* *}$ \\
\hline DRB1-SacIab/DRB1-MvaIbc/DQB1-TaqIaa/DQB1-HaeIIInn & 6 & 6 & 0.0012 \\
\hline DRB1-SacIab/DRB1-MvaIbc/DQB1-TaqIaa/DQB1-HaeIIImn & 8 & 3 & 2.3000 \\
\hline DRB1-SacIab/DRB1-MvaIbb/DQB1-TaqIaa/DQB1-HaeIIImm & 14 & 11 & 0.3460 \\
\hline DRB1-MvaIbc/DQB1-MvaIyy/DQB1-TaqIab/DQB1-HaeIIImn & 0 & 13 & $14.1600^{* *}$ \\
\hline DRB1-MvaIbb/DQB1-MvaIcc/DQB1-TaqIab/DQB1-HaeIIImn & 1 & 18 & $17.1439^{* *}$ \\
\hline DRB1-MvaIbc/DQB1-MvaIbb/DQB1-TaqIab/DQB1-HaeIIInn & 4 & 7 & 0.9280 \\
\hline DRB1-MvaIbc/DQB1-MvaIcc/DQB1-TaqIaa/DQB1-HaeIIImn & 0 & 2 & 2.0600 \\
\hline DRB1-MvaIbb/DQB1-MvaIcz/DQB1-TaqIaa/DQB1-HaeIIImn & 1 & 5 & 2.8292 \\
\hline
\end{tabular}

Note: $\chi^{2}>\chi_{0.01,1}^{2}=6.63, P<0.01 \cdot \chi^{2}>\chi_{0.05,1}^{2}=3.84, P<0.05 \cdot \chi^{2}<\chi_{0.05,1}^{2}=3.84, P>0.05$.

${ }^{*} P<0.05,{ }^{* *} P<0.01$.

In this study, analysis of polymorphisms of MHC$D R B 1 / D Q B 1$ by the PCR-RFLP method was performed, as well as screening of genetic markers of antiechinococcosis in Chinese Merino sheep. Artificial infection was used to verify the relationship between different haplotypes of polymorphic MHC gene loci and the resistance of echinococcosis, which would lay a theoretical foundation for sheep breeding of disease resistance in the future.

\author{
Abbreviations \\ MHC: Major histocompatibility complex \\ Ovar: Ovine MHC \\ OLA: Ovine lymphocyte surface antigen \\ PCR: Polymerase chain reaction \\ RFLP: Restriction fragment length polymorphism \\ C.E: Cystic Echinococcosis \\ A.E: Alveolar Echinococcosis \\ E.g: Echinococcus granulosus \\ E.m: Echinococcus multilocularis.
}

\section{Conflict of Interests}

The authors declare that there is no conflict of interests regarding the publication of this paper.

\section{Authors' Contribution}

Hong Shen and Guohua Han equally distributed to this paper.

\section{Acknowledgments}

We are grateful to the Mission 165, Ninth agricultural 264 ricultural division, Xinjiang Production and 265 Construction Corps for providing us with the experimental sheep. This study was supported 266 by the project of National Natural Science Foundation of China (Grant no. 30660124, Grant 267 no. 31260535, Grant no. 31060281) and Specialized Research
Fund for the Doctoral Program of 268 Higher Education (Grant no. 20106518110003).

\section{References}

[1] R. Hediger, H. A. Ansari, and G. F. Stranzinger, "Chromosome banding and gene localizations support extensive conservation of chromosome structure between cattle and sheep," Cytogenetics and Cell Genetics, vol. 57, no. 2-3, pp. 127-134, 1991.

[2] J. Klein, The Natural History of the Major Histocompatibility Complex, John Wiley and Sons, New York, NY, USA, 1986.

[3] P. Chardon, M. Kirszenbaum, and P. R. Cullen, "Analysis of the sheep MHC using HLA class I, II, and C4 cDNA probes," Immunogenetics, vol. 22, no. 4, pp. 349-358, 1985.

[4] W. J. Dai, A. Waldvogel, T. Jungi, M. Stettler, and B. Gottstein, "Inducible nitric oxide synthase deficiency in mice increases resistance to chronic infection with Echinococcus multilocularis," Immunology, vol. 108, no. 2, pp. 238-244, 2003.

[5] M. Despoina, T. B. Keith, A. E. Shirley, C. R. George, and J. M. Declan, "Haplotype characterization of transcribed ovine major histocompatibility complex (MHC) class I genes," Immunogenetics, vol. 57, pp. 499-509, 2005.

[6] W. Zhang, H. You, J. Li et al., "Immunoglobulin profiles in a murine intermediate host model of resistance for Echinococcus granulosus infection," Parasite Immunology, vol. 25, no. 3, pp. 161-168, 2003.

[7] P. C. Scott, J. F. Maddox, K. J. Gogolin-Ewens, and M. R. Brandon, "The nucleotide sequence and evolution of ovine MHC class II B genes: DQB and DRB," Immunogenetics, vol. 34, no. 2, pp. 80-87, 1991.

[8] S. Paterson, K. Wilson, and J. M. Pemberton, "Major histocompatibility complex variation associated with juvenile survival and parasite resistance in a large unmanaged ungulate population (Ovis aries L.)," Proceedings of the National Academy of Sciences of the United States of America, vol. 95, no. 7, pp. 37143719, 1998.

[9] F.-W. Schwaiger, D. Gostomski, M. J. Stear et al., "An ovine major histocompatibility complex $D R B 1$ allele is associated with low faecal egg counts following natural, predominantly Ostertagia 
circumcincta infection," International Journal for Parasitology, vol. 25, no. 7, pp. 815-822, 1995.

[10] K. T. Ballingall, K. Fardoe, and D. J. McKeever, "Genomic organisation and allelic diversity within coding and non-coding regions of the Ovar-DRB1 locus," Immunogenetics, vol. 60, no. 2, pp. 95-103, 2008.

[11] G. Sayers, B. Good, J. P. Hanrahan, M. Ryan, J. M. Angles, and T. Sweeney, "Major Histocompatibility Complex DRB1 gene: its role in nematode resistance in Suffolk and Texel sheep breeds," Parasitology, vol. 131, no. 3, pp. 403-409, 2005.

[12] P. M. Outteridge, L. Andersson, P. G. C. Douch et al., "The PCR typing of MHC-DRB genes in the sheep using primers for an intronic microsatellite: application to nematode parasite resistance," Immunology and Cell Biology, vol. 74, no. 4, pp. 330336, 1996.

[13] K. T. Ballingall, D. Miltiadou, Z.-W. Chai et al., "Genetic and proteomic analysis of the MHC class I repertoire from four ovine haplotypes,' Immunogenetics, vol. 60, no. 3-4, pp. 177-184, 2008.

[14] L. M. Herrmann-Hoesing, S. N. White, M. R. Mousel, G. S. Lewis, and D. P. Knowles, "Ovine progressive pneumonia provirus levels associate with breed and Ovar-DRB1," Immunogenetics, vol. 60, no. 12, pp. 749-758, 2008.

[15] M. A. Hohenhaus and P. M. Outteridge, "The immunogenetics of resistance to Trichostrongylus colubriformis and Haemonchus contortus parasites in sheep," British Veterinary Journal, vol. 151, no. 2, pp. 119-140, 1995.

[16] M. E. Azab, S. A. Bishara, R. M. R. Ramzy, N. M. Oteifa, L. M. El-Hoseiny, and M. A. Ahmed, "The evaluation of HLA$D R B 1$ antigens as susceptibility markers for unilocular cystic echinococcosis in Egyptian patients," Parasitology Research, vol. 92, no. 6, pp. 473-477, 2004.

[17] D.-A. Vuitton, G. Mantion, B. Bartholomot, P. Giraudoux, and S. Bresson-Hadni, "Parasite-host relationships and treatment," Bulletin de l'Academie Nationale de Medecine, vol. 192, no. 6, pp. 1103-1117, 2008.

[18] S. Harraga, V. Godot, S. Bresson-Hadni, G. Mantion, and D. A. Vuitton, "Profile of cytokine production within the periparasitic granuloma in human alveolar echinococcosis," Acta Tropica, vol. 85, no. 2, pp. 231-236, 2003.

[19] V. Godot, S. Harraga, I. Beurton et al., "Resistance/susceptibility to Echinococcus multilocularis infection and cytokine profile in humans. II. Influence of the HLA B8, DR3, DQ2 haplotype," Clinical and Experimental Immunology, vol. 121, no. 3, pp. 491498, 2000.

[20] S. Konnai, Y. Nagaoka, S. Takesima, M. Onuma, and Y. Aida, "DNA typing for ovine MHC DRB1 using polymerase chain reaction-restriction fragment length polymorphism (PCRRFLP)," Journal of Dairy Science, vol. 86, no. 10, pp. 3362-3365, 2003.

[21] M. Amills, C. Sulas, A. Sànchez, G. Bertoni, R. Zanoni, and G. Obexer-Ruff, "Structural characterization of the caprine major histocompatibility complex class II DQB1 (Cahi-DQB1) gene," Molecular Immunology, vol. 41, no. 9, pp. 843-846, 2004.

[22] S. Dematteis, M. Rottenberg, and A. Baz, "Cytokine response and outcome of infection depends on the infective dose of parasites in experimental infection by Echinococcus granulosus," Parasite Immunology, vol. 25, no. 4, pp. 189-197, 2003.

[23] M. M. Sissay, A. Uggla, and P. J. Waller, "Prevalence and seasonal incidence of larval and adult cestode infections of sheep and goats in eastern Ethiopia," Tropical Animal Health and Production, vol. 40, no. 6, pp. 387-394, 2008.
[24] M. Amills, O. Francino, and A. Sanchez, "Nested PCR allows the characterization of TaqI and PstI RFLPs in the second exon of the caprine MHC class II DRB gene," Veterinary Immunology and Immunopathology, vol. 48, no. 3-4, pp. 313-321, 1995.

[25] M. Amills, O. Francino, and A. Sànchez, "A PCR-RFLP typing method for the caprine Mhc class II DRB gene," Veterinary Immunology and Immunopathology, vol. 55, no. 1-3, pp. 255260, 1996.

[26] S. Dongxiao and Z. Yuan, "Polymorphisms of the second exon of MHC-DRB gene in Chinese local sheep and goat," Biochemical Genetics, vol. 42, no. 9-10, pp. 385-390, 2004.

[27] P. Feichtlbauer-Huber, M. J. Stear, R. Fries, and J. Buitkamp, "Reference-strand-mediated conformation analysis of MHC alleles: a new method for high-resolution typing of the Ovar$D Q B$ genes," Immunogenetics, vol. 51, no. 1, pp. 65-68, 2000.

[28] H. Liu, G. F. Su, S. H. Wei et al., "Association of human leucocyte antigen- $D R B$ and $-D Q B$ alleles with Eales' disease," Chinese Journal of Ocular Fundus Diseases, vol. 22, no. 2, pp. 90-93, 2006.

[29] M.-Y. Fang, X.-X. Hu, N. Li, and C.-X. Wu, "Polymorphism analysis of the exon 2 of SLA-DQB gene in Xiao Meishan, Zhong Meishan and Yorkshire pigs with PCR-RFLP," Acta Genetica Sinica, vol. 29, no. 8, pp. 685-687, 2002.

[30] K. Wang, D. X. Sun, R. H. Xu et al., "Polymorphism in upstream regulatory region of BoLA-DQB genes," Acta VEterinaria Et Zootechnica Sinica, vol. 36, no. 6, pp. 521-525, 2005.

[31] S. X. Gao, S. Z. Xu, J. Q. Li et al., "Analysis of polymorphisms of BoLA-DQA and DRB3 exon2 and the relationship between the gene and mastitis in dairy cattle," Acta VEterinaria Et Zootechnica Sinica, vol. 37, no. 4, pp. 317-320, 2006.

[32] T. H. Eiermann, F. Bettens, P. Tiberghien et al., "HLA and alveolar echinococcosis," Tissue Antigens, vol. 52, no. 2, pp. 124129, 1998. 

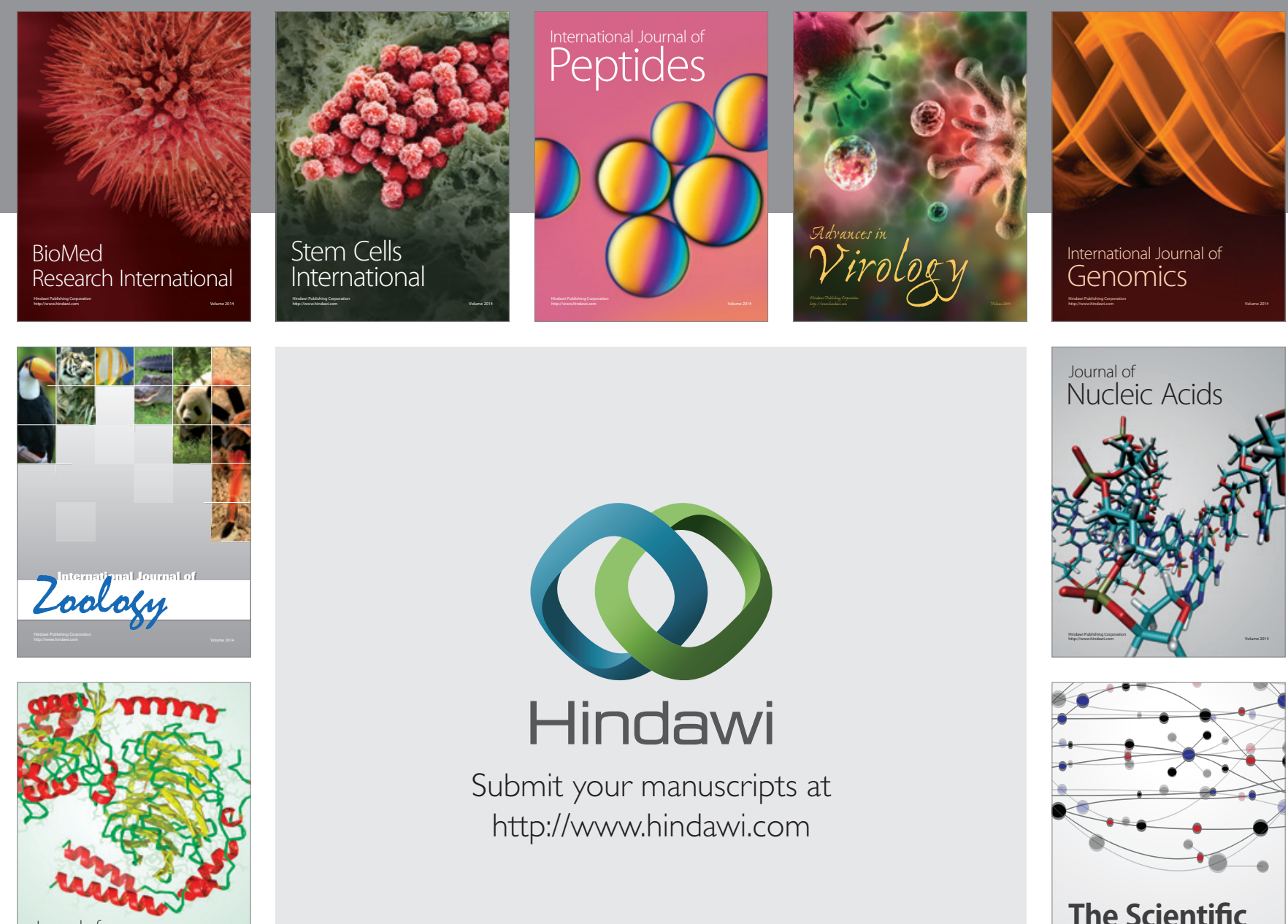

Submit your manuscripts at

http://www.hindawi.com

Journal of
Signal Transduction
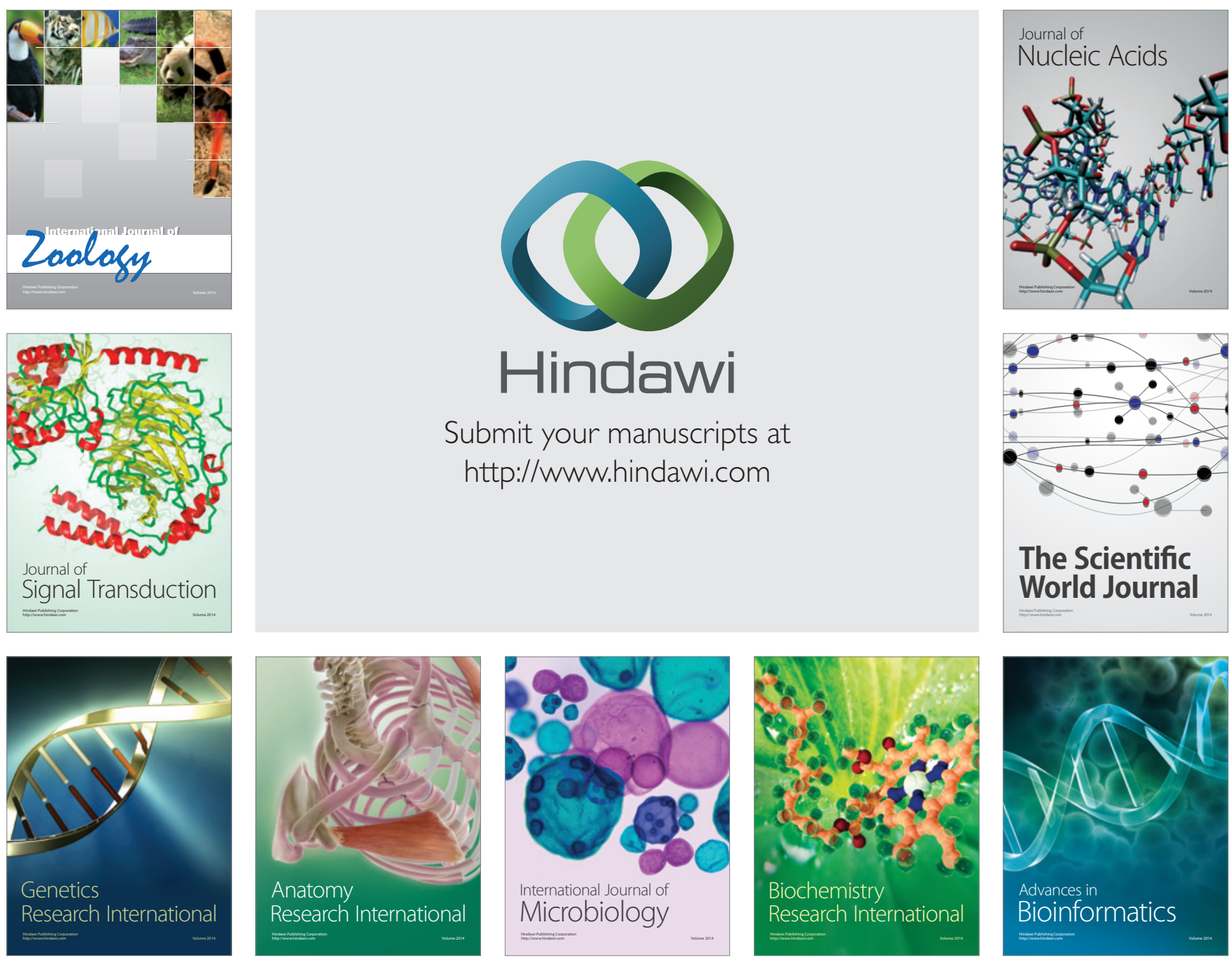

The Scientific World Journal
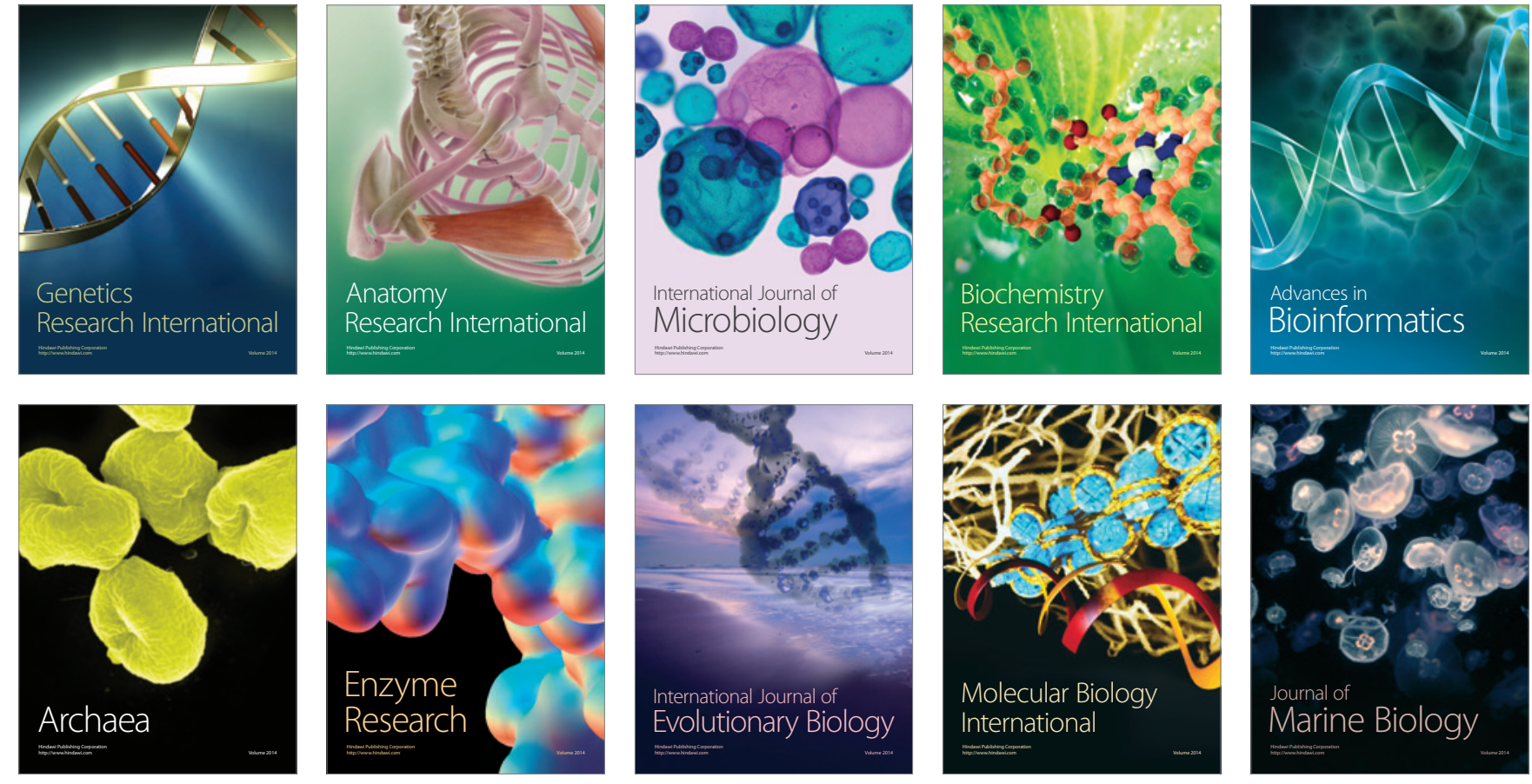